Article

\title{
Investigation of Bottlenecks in Supply Chain System for Minimizing Total Cost by Integrating Manufacturing Modelling Based on MINLP Approach
}

\author{
Mahboobehalsadat Hajmirfattahtabrizi $*$ and Huaming Song \\ Department of Management Science and Engineering, School of Economics and Management, \\ Nanjing University of Science and Technology (NJUST), Nanjing 210094, China; huaming@njust.edu.cn \\ * Correspondence: 715107020040@njust.edu.cn; Tel.: +86-150-4030-9652
}

Received: 20 December 2018; Accepted: 11 February 2019; Published: 20 March 2019

\begin{abstract}
In recent years, due to high pressure of expenses on supply chain systems and members, the decision makers in these situations are seeking to create policy and strategies to minimize the total cost for their supply chain process with low target price and future demands. Regarding this crucial issue, their studies on the implementation of supply chain issues and bottlenecks have observed the enormous and direct impact on company's financial performance and improve it systemically. In this paper, a well-known mixed integer nonlinear programming by multi-objective function is proposed to decide on reliable results for supply, production, and distribution system problems. The proposed mixed integer nonlinear programming model for multi-objective supply, production, and distribution problems is used to minimize the total cost for incurred sections and terms by decision makers. The obtained optimum solution and result are fulfilled by investigators and producers for planning how to adjust the investment and gain more accurate performances and implementations. Numerical results in plots and throughputs from MATLAB, using MINLP, showed that integrating the supply chain and mitigating the bottlenecks led to improve the system and decrease the total cost approximately $(19.73 \%)$, while running without negative effects of supply chain disturbances on total cost.
\end{abstract}

Keywords: bottlenecks; integration; multi objective; supply chain decision making; nonlinear programming; total cost

\section{Introduction}

The 19th C. was the earliest time that the term "supply chain management" was introduced in researches of military journals [1]. A supply chain management system with its application is gradually developed to compete with other chain management systems as competitors or rivals in marketplace to acquire the profits and meet the maximum order of customers. Recently, the supply chain is growing and has been a significant issue via globalization in markets, which are effective in creating a competitive relationship between the products and enterprises' profits. Either high customer service level or reducing logistics costs and marginal profits for the enterprises can be main goals. Lee et al. found that integration in supply chain as internal segments is a key factor in reducing the cost-containment and, still better, strategically integrating the supply chain with the suppliers [2]. Previously, the functions were operated independently, such as supplying, purchasing, manufacturing, processing logistics and transportation, distribution, scheduling, marketing, and customer service level through supply chain system. These functions are basically different but are intended to integrate strategically, even though their goals are not similar. The integration of supply, production, 
and distribution in manufacturing systems are key terms in risk conditions. In this case, we consider the model of manufacturing systems individually and also integrate the multi-objective problem, with the aim of minimizing the manufacturing total cost, including minimizing the cost of supply manufacturing system, production manufacturing system, and distribution manufacturing system. Vaart \& Donk identified that supply chain integration (SCI) is an important and main factor in supply chain performance [3].

In supply chain, the main factors are supply, production, and distribution operations. To fulfill the decision makers' and investors' goals and to maximize benefits, the system seeks to integrate these three functional segments of supply, production, and distribution that are recognized as crucial decisions. There are many conflicts on the objectives of this integrated decision-making system, so the system has to reduce the total cost and lead time, while the service level and demands must be increased. This paper is the study of decision making to minimize the total cost of integrated function of supply chain system through the key tools of the mixed integer nonlinear programming (MINLP) method. By approaching this certain arithmetical modelling, mixed integer nonlinear programming, the supply chain system is able to be multi-functional with multi-objectives, and to obtain the optimum solution and result for the current problem.

Current research seeks to obtain the optimum solution for finding the existing bottlenecks in performances by modelling the integer nonlinear programing as a minimizing model for cost supply, production, and distribution operations with defined multiple parameters in a clear period of time. Here, the main goal is how to manage and decide for investing the budget through all sections by customers' demand and in order. However, in real world problems, the costs and time of functions are uncertain and periodically changeable, as customers' demands are not fixed, so decision making is more complicated. Herein, in this problem, the essential parameters are defined and modified respectively through the manufacturing functions individually. In summary, the lost costs of manufacturing functions, known as bottleneck, would be compared with the integrated model of manufacturing function. Mixed Integer Non-Linear Programming (MINLP) is used to mitigate the bottleneck while raising the profitability for the supply chain system.

This research paper proceeds as follows: a brief literature review on integrating supply chain manufacturing problem is presented in Section 2. In Section 3, the structure of supply chain in a model, description of objectives, and current study bottleneck are presented. Section 4 presents a developed model for integrating supply chain functions for cost. In Section 5, the analysis of data for the case study in multi-objective mixed integer nonlinear programming (MINLP) method has been provided. Finally, in Section 6, the conclusions are discussed based on the given optimum solution from numerical data.

\section{Literature Review}

In this section, we consider the results and methods applied for integrated supply chain system by researchers and authors. According to the relevant studies about supply chain manufacturing process, Sawik had worked on an integrated supply, production, and distribution scheduling for joint selection of suppliers by using mixed integer linear programming under regional risk to minimize the cost and maximize the service level [4]. Jabbarzadeh et al. used a realistic production-distribution planning model to robust interruptions and demand uncertainties [5]. Nemati \& Alavidoost developed three bi-objective f-MILP models for sales and operational planning to minimize the total SC cost and maximize the customer service level [6]. Jolai \& Gharaei proposed a multi-agent scheduling problem with distribution decisions in a multi-factory supply chain by using a multi-objective integer programming model based on decomposition with Bees algorithm (MOEA/D-BA) to achieve the Pareto solution, in order to minimize the tardiness of jobs while minimizing the total cost [7]. Leung et al. employed an integrated production and delivery model with single and multiple vehicles by using a multi-objective mathematical model of PD-NSGA-II algorithm to improve the performance of scheduling and evaluating in pull supply chain [8]. Rohemer and Billaut surveyed the production and 
outbound distribution scheduling model to minimize the total cost function by using MILP [9]. Foerstl et al. made an attempt to investigate how purchasing and supply chain management (PSM) decisions affect the supply chain as a whole and are affected by that. They also showed the contribution of PSM to supply chain, network integration, and vast effectiveness, as internal functions that are more permeable, and more complex external supply chain environments [10]. Khan et al. developed an integrated model of supply chain for vendor-buyer inventory policy with the aim of minimizing the joint annual cost of lot size and supply chain by using EPQ policy, and also by finding the optimal batch size and number of shipments for each [11]. Chung and Kwon proposed a systematic and integrated pharmaceutical supply chain management to measure the impact of pharmaceuticals' perishability and to capture the price fluctuations on a supply chain through dynamic equilibrium solution [12]. Aqlan and Lam used a fuzzy integrated framework for supply chain to identify the risk factors and assess their impacts qualitatively and quantitatively [13]. Hu et al. investigated integrated supply chain on the economic multi-objective model to maximize the profit for 20-year chemical production systems and minimize the life cycle greenhouse gas emissions by minimizing the availability and facility capital costs through mixed integer linear programming that would optimize the locations for the woody biomass and capacity of distributed preprocessing hubs [14]. Diabat and Al-salem focused on maximizing the profitability and minimizing the operational costs by integrating a stochastic two-echelon supply chain by using Genetic Algorithm and solving by GAMS [15]. Diabat and Deskoors developed an integrated supply chain model of a capacitated multi-echelon joint location-inventory system by using GA and assigning each retailer to one special warehouse, while each warehouse can serve multiple retailers with the aim of minimizing the cost of operating the supply chain [16]. Gunasekaran et al. investigated a research and application in logistics and SCM strategies to minimize the operations cost and improve their suppliers' performance, enabling them to establish a new benchmark in order to determine the value added to operations and improve business processes [17]. Shaye et al. searched for an integrated model for supply chain to minimize the cost and time cycle of products and service levels, while increasing the customer's demand in order quantity in the internal market or global market [18]. Pishvaee et al. surveyed a biodiesel supply chain network in order to assess and propose a mathematical programming model that optimized the data, location, and capacities of JCL cultivation centers and other locations in their problem to take suitable strategic and tactical level decisions related to biodiesel supply chain planning by using a unified DEA model [19]. Ferrell et al. focused on the integrated production and distribution scheduling practical problem of a perishable product to minimize the total cost, including fixed cost and variable cost, through using a mixed integer programming based on evolutionary Genetic Algorithms [20]. Zegordi and Marandi studied the integrated production and distribution scheduling with the aim of minimizing the interval time between the production and distribution about some special types of products, such as foodstuffs, by using a mixed integer nonlinear programming method [21]. Moin and Yuliana researched an integrated production, inventory, and distribution routing problem that is aimed at minimizing the total cost by using a scatter search algorithm [22]. Azadian et al. investigated an integrated production scheduling and transportation planning to minimize the total cost of fulfilling orders by using a mixed integer programming model based on algorithm [23]. In his book, Stadtler researched the companies that become a part of a supply chain in order to improve competitiveness in the long run and provide a superior customer service in the minimum cost and time while overcoming the barriers [24]. Bektas et al. described an integrated model that optimized the strategic and tactical decisions of a closed loop supply chain to minimize the costs of transportation, purchasing, refurbishing, and operating disassembly of workstations, by using a nonlinear mixed integer programming formulation [25]. Gale et al. developed a mathematical model to optimize the integrated supply chain planning and decision making processes to make the strategic, tactical, and operational decisions involved for suppliers, manufacturers, and customers [26]. The debottlenecking of the integrated biomass supply chain performance is proposed through using a conventional P-graph method that is applied and considered to identify the bottleneck in process of biomass product life cycle by academicians, design 
engineers and project managers [27]. Specific bottlenecks are identified as the factors which impact IFA supply chain and consist of forecasting procurement, storage, and disposal to test iron and folic acid, according to the government health system IFA supply and distribution system [28]. In construction industry problem of India used a multi-objective linear programming to analyze and prioritize the main drivers of green supply chain management (GSCM) including the suppliers, customers, internal drivers and environment that ranks by decision makers or board of NCR [29]. Supply of coal, boiler operations, flue gas emissions, waste disposal, transmission losses, distribution losses, and consumption are identified as bottlenecks in green supply chain in the power industry, one of the leading polluters in the world [30]. Identifying the sustainable bottlenecks at planning phase consists of economic, environmental, or social dimensions that are fixed by using debottlenecking in a preliminary step of integrated biomass supply chain (configuration a plant) through principal component analysis (PCA) method is suggested to decision makers [31]. The real-time supply chain visibility technology emergencies in developing management capabilities has enabled the managers and decision-makers to enhance the ability to identify the bottlenecks of supply chain flow of convergence of cloud computing, distributing computing, data integration technologies, and mobile technology by using analytical capability development [32].

\section{Integrated SCM Model}

Figure 1 is considered to be formulated as an integrated model of multi-segment for supply, production, and distribution in supply chain system that can be expanded based on jointed parts or segments.

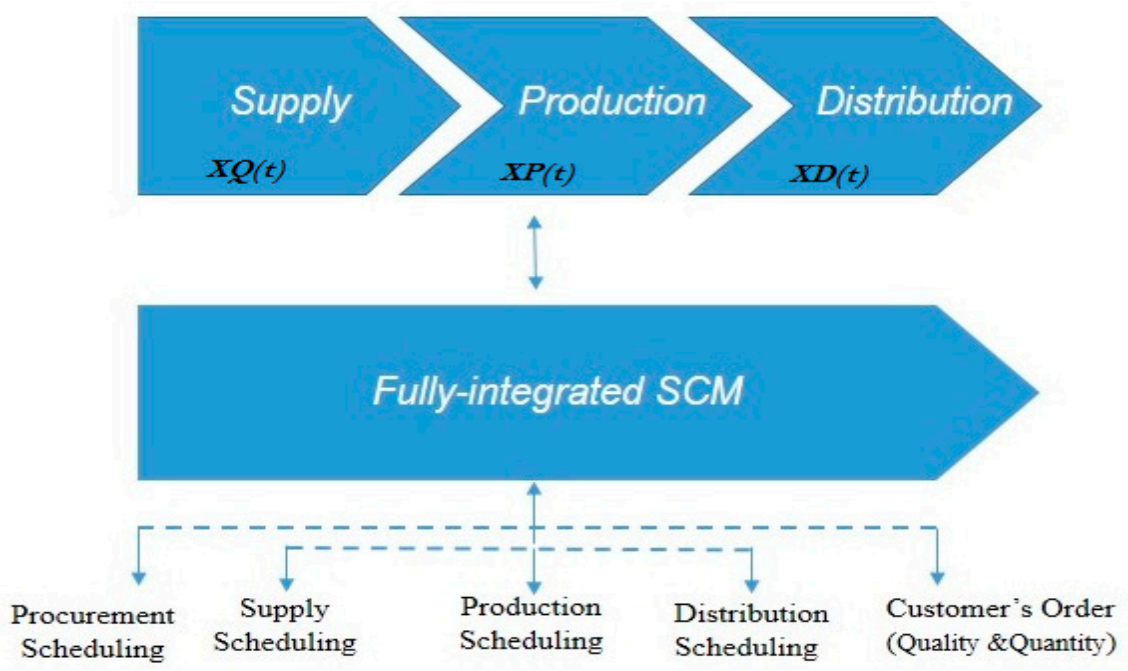

Figure 1. The fully integrated supply, production and distribution Model. Input supply $X^{Q}(t)$, Production $X^{P}(t)$ and Distribution $X^{D}(t)$.

In the Figure $1, \mathrm{X}^{\mathrm{Q}}(\mathrm{t})$ is indicated as an input step in manufacturing supply chain process, $\mathrm{X}^{\mathrm{P}}(t)$ is the produced amount of materials in production stage, and $X^{\mathrm{D}}(t)$ is the amount of distributed products in time $(t)$. At this step, evaluating the logical response to these questions is important, such as how many units of raw material are purchased in need and how many must be produced and distributed. However, some responses and reasons would depend on the previous step of the process, since the amount of investment is shared among all segments of supply, production, and distribution while being cost-effective so that the total cost increases by even one excess product and extra amount of inventory. In the current case, the supply chain integrated in the model would include a collection of three segments of supply, production, and distribution, and achieve the purpose and prove the hypothesis of the problem. 
As can be shown in Figure 2, the expansion of the services in the manufacturing industry has already been illustrated and developed on many levels of this conceptual model for supply chain system. However, the model has highlighted the manufacturing industry structures or elements and all the implementations and performances have been limited to the services in levels from beginning point to end point. The first step of studying the model as a supply chain service is inclusive of the suppliers for providing the raw materials. After the suppliers, the components, production, distribution, and consumption are parted in this model. All the services and parts describe the process of manufacturing products, inventory control system, and replenishment. In this paper, we illustrate a logical structure and simulations model based on a product-oriented approach. This product-oriented model based on costs makes up a conceptual model. The modeling acts as an efficient simulation in practice and performance particularly. This current conceptual model of supply chain system emphasized the participation and coordination of many different parts while composing providers of raw materials, integrators of supply chain system segments, and customers' demands. That bottleneck may happen in any of these sections. The following section is pointed to existing bottlenecks and investigating in supply chain system and describing in detail.

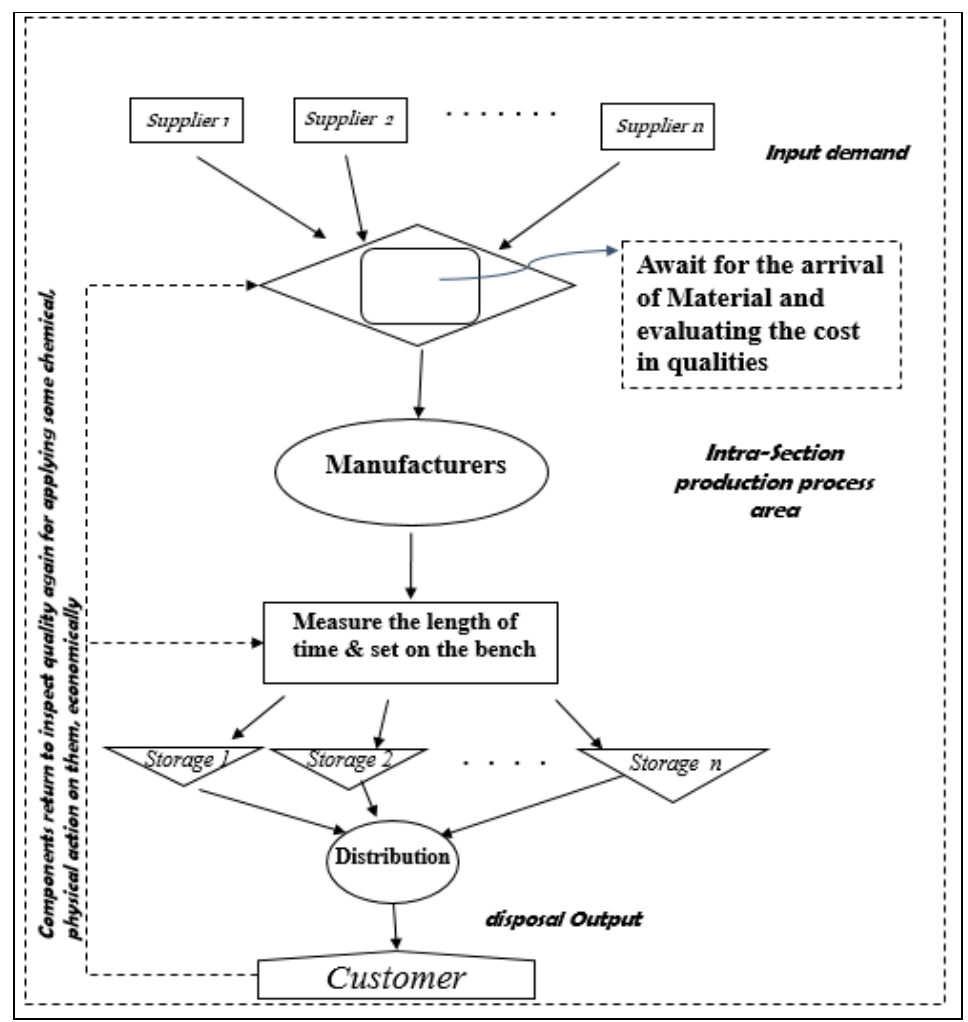

Figure 2. Conceptual Model for Flow process chart of manufacturing supply chain system.

\subsection{The Challenge of Supply Chain Bottlenecks}

A bottleneck in a supply chain is like a cog in the process, and occurs when the predecessor step is done earlier or faster than the time when the next step or operation will be used to fulfill the goal, because of poor productivity or labors or machines not performing efficiently. In this occasion, the operation lasting longer than usual is identified as the bottleneck of the supply chain management system. All the losses and inefficiencies or low speed of operating in manufacturing system are just caused by this bottleneck that negatively affects system's growth and progress to enhance the profit for manufacturing supply chain system. The managers and decision makers must identify and fix or remove the bottlenecks; that is a vital and critical issue for manufacturing supply chain processing system. For example, with using wind power generation in electricity markets, there is a bottleneck in 
zonal placement of spinning reserve that inhibits the deliverability of reserve that solves the increasing total cost by co-optimization model [33]. The bottleneck can be in sparking communication when there is an increase in consensus nodes that can cause problems for the large-scale applications and may increase the cost of communication. This problem and bottleneck is solved by proposing a scalable dynamic multi-agent hierarchical PBFT algorithm (SDMA-PBFT) that affects network nodes directly, from great node to the next node according to the number of nodes wrongly in the network, such as the number of consensus nodes which seriously hinder large-scale applications as multi-agent practical byzantine in permissioned block chain [34]. For example, in healthcare, where the processes are complex and multi-disciplinary in nature and have bottlenecks that are identified in two parts (pre-operative and post-operative process) resulting from the absence of certain records, staff or nature specialty, and solved by a goal-driven process evaluation method based on PM [35]. Bottlenecks may present as potential or shifting in operation mode such as rerun, low output in amount, or machine (tools) breakdowns in catastrophic events such as fire or operator carelessness that can continue manufacturing just by replacing another new machine or tool. The other, shifting type is rare to find and identify and mitigate or solve the causes [36]. In supply chain manufacturing operation system, the weakest link in entire lifecycle of a product is known as bottleneck, usually in financial problems of plant. By investigating theories on bottlenecks in supply chain network, the supply chain bottlenecks would be explored, and managers can solve the complexities by using methods such as Supply Chain Network (SCN) and Network Theory-based [37]. The results achieved the bottlenecks based on models and calculations. Since the beginning, by using the abstracted models of supply, production, and distribution individually and finally by an integrating model, a significant different in final model result is provided as well as aggregate results from Supply, Production, and Distribution (SPD) models that shows main reduction in total cost while containing quality of product [38].

In next section, we are going to describe the supply chain models for minimizing the total cost of systems that results in finding a preventative process for bottlenecks through the multi-objective modelling of supply, production, and distribution cost models individually.

\subsection{Supply, Production and Distribution Models}

The multi-time period linear analytical models are formulated with the aim to minimize the total cost and non-contractual expenses as the basic investing amount through the supply chain manufacturing process, storage, inventory, demand, maintenance of the goods, and distribution. Thus, the considered terms are designed as follows;

1. The demand rate is defined by ordering, just increasable by inventory control policies.

2. The considered cost for supply chain manufacturing system is concluded from fixed and variable.

3. The similar attitudes for selecting suppliers, producers, or manufacturers and distributors to achieve the goal strategically.

\subsubsection{Model Parameters}

As described in the above sections, parameters, indices, sets, and decision variables in model as follows. In Table 1, the multi-objective linear programming variables and parameters with their interactions are determined by the properties on supply, production, and distribution segments in period of time $(t)$. 
Table 1. Determination the parameters with definition in Supply, Production and Distribution Model.

\begin{tabular}{cl}
\hline Parameters & \multicolumn{1}{c}{ Definition } \\
\hline$(t) \in T$ & Set of time periods \\
$Q, P, D$ & Parameters instead of Supply, Production and Distribution \\
$Z^{Q}(t), Z^{P}(t), Z^{D}(t)$ & Decision variables for consuming in time $(t)$ \\
$X^{Q}(t), X^{P}(t), D(t)$ & Terms for cost of product in supply, production and distribution in time $(t)$ \\
$C^{Q}(t), C^{P}(t), C^{D}(t)$ & Terms for variable costs in supply, production, distribution in time $(t)$ \\
$h^{Q}(t), h^{P}(t), h^{D}(t)$ & Holding cost in supply, production and distribution in time $(t)$ \\
$I^{Q}(t), I^{P}(t), I^{D}(t)$ & Inventory cost in supply, production and distribution in time $(t)$ \\
$A^{Q}(t), A^{P}(t), A^{D}(t)$ & Target price in supply, production and distribution in time $(t)$ \\
$Q_{d w}, P_{d w}, D_{d w}$ & damaged item Volume (damage \& wastes) in Supply, Production, and Distribution \\
$M$ & A large amount (countless) \\
$D$ & Demand \\
\hline
\end{tabular}

\subsubsection{The Cost Model of Supply in Supply Chain Manufacturing System}

Accordingly, the objective function for each section of supply, production, and distribution system in a mathematical formulation of the proposed models are detailed and presented below with the aim of minimizing the supply manufacturing system cost. The proposed models containing the operational conditions of supply, production, and distribution to find the feasible solutions for decision variables properly. The objective of the following models is to minimize the total cost for the given multi-time periods. The total cost in each segment of supply, production, and distribution are included in the objective function, consisting of total costs in purchasing, operational costs, and warehouses and distributing costs containing transportation costs in the process, as shown in sequence in equations.

Total Cost $(t)=$ purchasing cost of the materials + Variable cost + Holding cost of inventory.

$$
\operatorname{Min}=\sum_{t=1}^{T} A^{Q}(t) Z^{Q}(t)+C^{Q}(t) Q(t)+h^{Q}(t) I^{Q}(t)
$$

s.t.

$$
\begin{gathered}
X^{Q}(t) \leq A^{Q}(t) \\
\sum_{t=1}^{\mathrm{T}} Q(t) \geq \sum_{t=1}^{\mathrm{T}} P(t) \quad t=1,2,3, \ldots, \mathrm{T} \\
I^{Q}(t)=[(Q(t)-Q d w(t))-d(t)]+I^{Q}(t-1) \quad t=1,2, \ldots, T \\
X^{Q}(t) \leq \mathbf{M} Z^{Q}(t) \\
d(t), Q(t), P(t), X^{Q}(t) \geq 0 \text { and integer }
\end{gathered}
$$

\subsubsection{The Cost Model of Production in Supply Chain Manufacturing System}

The objective function for minimizing the costs in production manufacturing system is considered by following the constraints;

Total Cost $(t)=$ cost of materials in production + Variable cost of production + Holding cost of inventory

$$
\operatorname{Min}=\sum_{t=1}^{\mathrm{T}} A^{P}(t) Z^{P}(t)+C^{P}(t) P(t)+h^{P}(t) I^{P}(t)
$$

s.t.

$$
\begin{gathered}
X^{P}(t) \leq A^{P}(t) \\
\sum_{t=1}^{\mathrm{T}} P(t) \geq \sum_{\mathrm{t}=1}^{\mathrm{T}} D(t) \quad t=1,2, \ldots, T
\end{gathered}
$$




$$
\begin{gathered}
I^{P}(t)=\left[\left(P(t)-P_{d w}(t)\right)-d(t)\right]+I^{P}(t-1) \\
X^{P}(t) \leq M Z^{P}(t) \\
X^{P}(t), P(t), D(t), d(t) \geq 0 \text { and integer }
\end{gathered}
$$

\subsubsection{The Cost Model of Distribution in Supply Chain Manufacturing System}

The distribution objective function and the constraints are presented here with regard to the aim of the problem for minimizing the distribution costs in logistics and warehouses as below;

Total Cost $(t)=$ Cost of materials in distribution + Variable cost of distribution + Holding cost of inventory.

$$
\operatorname{Min}=\sum_{t=1}^{\mathrm{T}} A^{D}(t) Z^{D}(t)+C^{D}(t) D(t)+h^{D}(t) I^{D}(t)
$$

s.t.

$$
\begin{gathered}
X^{D}(t) \leq A^{D}(t) \\
\sum_{t=1}^{T} D(t) \geq \sum_{t=1}^{T} d(t) \quad t=1,2, \ldots, T, \\
I^{D}(t)=\left[\left(D(t)-D_{d w}(t)\right)-d(t)\right]+I^{D}(t-1) \\
X^{D}(t) \leq M Z^{D}(t) \\
X^{D}(t), \quad d(t), D(t) \geq 0 \text { and integer }
\end{gathered}
$$

As observed above, each objective function is being made with the aim of minimizing the costs of the manufacturing segments of supply, production, and distribution independently. The first constraint of each cost model is expressed; the quantity of sources in supply or production or distribution. The second constraint is used for responding to the forecasting demand in the above three models, as the value of demand in supply, production or in distribution segments according to needs and required items in a period of time $(t)$. The third constraint is indicated as the inventory level of product in supply, production and distribution that has the volume, remaining from the previous inventory in past and in addition with the last quantity of $Q(t), \boldsymbol{P}(t)$ and $\boldsymbol{D}(t)$ after reducing the damaged items and required amount of demands in each section from supply, production and distribution while the remaining amount will add to the recent inventory from the past. The fourth constraint is expressed as the relation among $X^{Q}(t), X^{P}(t)$, and $X^{D}(t)$ that are calculated as the amount in supply, production, and distribution to be less than the decision variables involved; $Z^{\mathrm{Q}}(t), Z^{\mathrm{P}}(t)$ and $Z^{\mathrm{D}}(t)$ in a period of time $(t)$, with the coefficient of a large number of $\mathrm{M}$ (countless amount) while making the value of decision variables as much. The fifth constraint is included of each variable of $X^{Q}(t)$ and $X^{P}(t)$ and $X^{D}(t)$, must be affirmative, and the quantities of variables $Z^{Q}(t)$ and $Z^{P}(t)$ and $\mathrm{Z}^{\mathrm{D}}(t)$ equals to at least zero and at most one.

\section{Developed Model}

As mentioned above, we have proposed a modeling approach to measure and analyze the surplus costs and values of supply, production, and distribution implementation. In this approach, the decision makers decide the importance of goal functions and, following this, use membership functions for each objective function in which the functions are flexible for any change to use in actual problem by the decision makers partly. As predicted in Figure 1, the three multi-segment S, P\&D models in integrated framework are seeking to optimize the total chain's performance costs. According to separately measuring and minimizing the scheduling and performance cost for finding and identifying the bottleneck, it is possible to prepare the appropriate individual operation scheduling in each, while one extra and noncontract implement may be caused to lose money or overinvest in the manufacturing process without planning. However, the integrated model can cover this problem while solving and 
controlling it, even while mitigating the bottleneck that can improve the system processing costs by decision makers' sharing the investment.

\subsection{Integrating Total Cost functions}

The parameters and variables of problem in objective function affect significantly on the manufacturing system in optimizing the model and reducing fact the total cost. The researchers can consider more parameters in the related sections and operating parts of supply chain system to analyze the problems and obtain the best solution for solving the supply chain cost problem. However, the manufacturing supply chain is seeking to increase competitive performance in global market by providing efficient and effective tools than can be gain advantages for their industry as a supply chain processing system [39]. It is demonstrated how firms are using technology for the integration of avenues accessible to achieve the advantages in satisfying the needs of market sections profitability [40].

Some hypotheses can be considered in this part for cost in integrated manufacturing functions:

- There is just one supplier used for providing the raw material in this model.

- The holding and maintenance costs in all models of supply, production, and distribution are considered and can be supposed to be unchanged.

- The quantity for the suppliers and the plant is defined.

- The demands for the plant manufacture and production is based on customer's order while the quantity is obvious and would be modified per period of time.

- $\quad$ The periods are determined as $\mathrm{t}=1,2,3, \ldots, \mathrm{T}$.

- The materials produce one product

- One center for distributing is considered.

Each one of the above hypotheses would be expandable. The obtained Model by integrating costs is as follow;

$$
\begin{aligned}
\operatorname{Min}=\sum_{t=1}^{T} A^{Q}(t) & Z^{Q}(t)+A^{P}(t) Z^{P}(t)+A^{P}(t) Z^{D}(t)+C^{Q}(t) Q(t)+C^{P}(t) P(t) \\
& +C^{D}(t) D(t)+h^{Q}(t) I^{Q}(t)+h^{Q}(t) I^{P}(t) \\
& +h^{D}(t) I^{D}(t)
\end{aligned}
$$

s.t.

$$
\begin{gathered}
X^{Q}(t) \leq A^{Q}(t) \\
X^{P}(t) \leq A^{P}(t) \\
X^{D}(t) \leq A^{D}(t) \\
\sum_{t=1}^{\mathrm{T}} Q(t)+I^{Q}(t-1) \geq \sum_{t=1}^{\mathrm{T}} P(t) \quad t=1,2,3, \ldots, T \\
\sum_{t=1}^{\mathrm{T}} P(t)+I^{P}(t-1) \geq \sum_{t=1}^{\mathrm{T}} D(t) \quad t=1,2,3, \ldots, T \\
\sum_{t=1}^{T} D(t)+I^{D}(t-1) \geq d(t) \quad t=1,2,3, \ldots, T \\
I^{Q}(t)=\left[\left(Q(t)-Q_{d w}(t)\right)-d(t)\right]+I^{Q}(t-1) \\
I^{P}(t)=\left[\left(P(t)-P_{d w}(t)\right)-d(t)\right]+I^{P}(t-1) \\
I^{D}(t)=\left[\left(D(t)-D_{d w}(t)\right)-d(t)\right]+I^{D}(t-1) \\
X^{Q}(t)-M Z^{Q}(t)<0
\end{gathered}
$$




$$
\begin{gathered}
X^{P}(t)-M Z^{P}(t)<0 \\
X^{D}(t)-M Z^{D}(t)<0 \\
(t), Q(t), P(t), D(t), X^{Q}(t), X^{P}(t), X^{D}(t) \geq 0 \text { and integer }
\end{gathered}
$$

The analytical discrete-time chart model is formulated to minimize the total operational costs in the whole system of the supply chain. The system is minimizing the total cost through integrating the supply, production, and distribution models and functions into an aggregate objective function including all holding costs for the inventory in each with achieving the main goal in current supply chain system. As constraint one shows, the cost for providing raw materials is less than or equal to target unit price. In each period of time, the cost of manufactured products as second part of supply chain process is less than or equal to considered target unit price in constraint two. Constraint three presents the cost of distributed product as less than or equal to the considered target price in supply chain. Constraints four to six determined the product's operational volume with last inventory being greater than or equal to the amount or volume of distributing products in the period of time, while the amount of distributing products to warehouses must be large enough to respond to demands in conventional time for delivery. In constraints seven, eight, and nine, the volume of inventory in each level of supply, production, and distribution depends on the remaining products or materials from the last time and having planned to provide or produce the required amount for the next step of operation process in supply chain manufacturing system. Actually, the inventory level of supply should be greater than the level of production needs, the inventory level of production greater than the level of distribution needs, and inventory level of distribution more than the final demands. The rest of the constraints, ten, eleven, and twelve were described in the above models individually. This illustrative model can be applied and proposed for manufacturing systems of spare-parts or auto-parts and other industries. Here, for solving and obtaining the optimal result of this problem, we have used MATLAB software. It is also suggested that the current model can be solved and optimized by software LINGO and GAMS.

\subsection{Priority of Implementation of Cost Model Individually or in Integrated Form}

By comparing these two phases, we can make a decision about the operations for each segment and scheduling for manufacturing in future, since the total time for making a product in each manufacturing segment of supply, production, and distribution is determined on operation. Meanwhile, the total time and cost in integrated form either have completed product or are suitable for manufacturing regarding the lower level in cost and time as well. Therefore, the operation time and cost for the integrated model is adjusted by a computational and mathematical model that results in optimal deterministic solution by applying MINLP in MATLAB through depicting the plots in each phase. The managers must shorten or mitigate the wasted time between two consecutive operations to improve the system functionally that leads to positive effects on customers' demands and advance scheduling time. The integrating model can keep the balance in time of operations and intervals but a separate model of each segment is impossible and changeable. Therefore, decision making of manufacturing could be dynamic rather static in a separate real-world framework.

\section{Implementation in AAC Industry (Numerical Case Study)}

The problem is in sharing total accessible budget in operations of supply-production-distribution manufacturing segments at Autoclaved Aerated Concrete (AAC) Blocks Plant plant as current case study. Through performances there are bottlenecks that increase the total cost and sometimes the production line stops the production suddenly, while the supply chain system cannot continue product enhancement. Though the implementations in each section of plant are complex, the performances are not similar in variant lines of production while having multifunctional machines that produce the product (light weighted blocks) in different size, which consume about five raw materials from varieties of suppliers 
that decision makers will choose suppliers in priorities to provide the essentials in time and cost. The raw materials are included of cement, Aluminum mash, lime, Silica, Gypsum mash, and logistic costs are different in shipping. Also, delivery costs to end-users or customers are different. As the provided materials must be tested on normality and activation in chemical and physical laboratory before combining with the other normalized and activated materials in mixer, even though the quality of each one is different in degree of temperature in production, but without respecting this, we consider and measure the operation time of well-mixed material in each operational segment to identify the congestion and bottlenecks. In integrated model, the non-contractual time and cost can be used and consumed for the other postponed functions in process of supply chain, but in separate framework or model, the time for each operation is fixed and allocated to its applications as controlled by managers and decision makers of manufacturing, and the lack of time in operation according to contractual time reflects on the preparing the customer's demand and is chaos for the following sections in controlling that caused to bottleneck in supply chain system.

Here, in this article, the problem is solved by using MINLP through MATLAB, a mathematical programming software to obtain the computations and present the plot for each operation while comparing together and with mixed integer modelling thoroughly. The programs are run on Windows 8. The multi- time step linear analytical data of supply model, production model and distribution model are considered from Tables $2-4$. Each period depends on ordering time and delivery time that lasts 1-3 months.

Table 2. Supply Model result.

\begin{tabular}{ccccc}
\hline Period Parameter & $\mathbf{1}$ & $\mathbf{2}$ & $\mathbf{3}$ & $\mathbf{4}$ \\
\hline$d(t)$ & 80 & 80 & 70 & 90 \\
$A^{Q}(t)$ & 200 & 200 & 200 & 200 \\
$c^{Q}(t)$ & 2 & 4 & 4 & 2 \\
$h^{Q}(t)$ & 1 & 1 & 1 & 1 \\
$Z^{Q}(t)$ & 100 & 100 & 100 & 100 \\
$X^{Q}(t)$ & 200 & - & 30 & 90 \\
\hline Total cost in Supply & \multicolumn{5}{c}{1148} \\
\hline
\end{tabular}

Table 3. Production Model result.

\begin{tabular}{ccccc}
\hline Period Parameter & $\mathbf{1}$ & $\mathbf{2}$ & $\mathbf{3}$ & $\mathbf{4}$ \\
\hline$d(t)$ & 80 & 80 & 70 & 90 \\
$A^{P}(t)$ & 200 & 200 & 200 & 200 \\
$C^{P}(t)$ & 6 & 3 & 6 & 3 \\
$h^{P}(t)$ & 1 & 1 & 1 & 1 \\
$Z^{P}(t)$ & 200 & 200 & 200 & 200 \\
$X^{P}(t)$ & 80 & 150 & - & 90 \\
\hline Total cost in & & \multicolumn{3}{c}{1674} \\
Production & & & \\
\hline
\end{tabular}

Table 4. Distribution Model result.

\begin{tabular}{ccccc}
\hline Period Parameter & $\mathbf{1}$ & $\mathbf{2}$ & $\mathbf{3}$ & $\mathbf{4}$ \\
\hline$d(t)$ & 80 & 80 & 70 & 90 \\
$C^{D}(t)$ & 4 & 8 & 3 & 5 \\
$h^{D}(t)$ & 1 & 1 & 1 & 1 \\
$Z^{D}(t)$ & 300 & 300 & 300 & 300 \\
$X^{D}(t)$ & 80 & 80 & 70 & 90 \\
\hline Total cost in & & & & \\
Distribution & & & & \\
\hline
\end{tabular}


The result is obtained by MATLAB so that the parameters according to Table 2 in Supply Model are included of $\mathrm{d}(\mathrm{t}), \mathrm{A}^{\mathrm{Q}}(\mathrm{t}), \mathrm{C}^{\mathrm{Q}}(\mathrm{t}), \mathrm{h}^{\mathrm{Q}}(\mathrm{t}), \mathrm{Z}^{\mathrm{Q}}(\mathrm{t}), \mathrm{X}^{\mathrm{Q}}(\mathrm{t})$ in certain periods of $t_{1}, t_{2}, t_{3}$ and $t_{4}$.

In Table 2, the supply costs in period 2 and 3 are more than period 1 and 4 . Meanwhile by spending higher cost in period 3, the sustainable production was in periods 2 and 4 . As shown in distribution model in Table 3, with respect to constraint for demand responding in each period, it is signified to transfer the products as contractual value and quantity. In Table 4, the integrated total cost model is presented in supply, production, and distribution according to the area and circumstances for supply, production, and distribution manufacturing segments. The costs are scaled and estimated in each segment by range of implementation through manufacturing process according to amount of raw material, inventory, production, and logistics or transportation system from first to fourth period of time in this measurement.

As depicted in Tables 2-5, the operation cost for the supply of raw materials for this plant is about 1148, while the operation cost for the production is 1674 and the operation cost for distribution channel is 2234 . The total optimization cost for all three segments is measured about 5056 but by respecting to the total cost in integrated model in Table 5, it is calculated by MATLAB to be about 4058 (total cost reduced approximately 19.73\%). As results shown in tables and programs, it is obvious that the integrated cost model was more effective than the segment cost model in order to minimize the expenses and to invest. This problem will be solved by repeating the numbers and obtain an optimized responds by MATLAB. The four-time periods linear analytical models are considered in consecutive periods of time for estimating the scales and costs.

Table 5. The Total cost of integrated manufacturing functions as Optimum result.

\begin{tabular}{ccccc}
\hline Period Parameter & $\mathbf{1}$ & $\mathbf{2}$ & $\mathbf{3}$ & $\mathbf{4}$ \\
\hline$X^{Q}(t)$ & 20 & 30 & - & 90 \\
$X^{P}(t)$ & 80 & 150 & - & 90 \\
$X^{D}(t)$ & 80 & 80 & 70 & 90 \\
\hline Total cost & \multicolumn{5}{c}{4058} \\
\hline
\end{tabular}

The result is obtained by MATLAB so that the parameters according to Table 2 in Supply Model are included of $\mathrm{d}(\mathrm{t}), \mathrm{A}^{\mathrm{Q}}(\mathrm{t}), \mathrm{C}^{\mathrm{Q}}(\mathrm{t}), \mathrm{h}^{\mathrm{Q}}(\mathrm{t}), \mathrm{Z}^{\mathrm{Q}}(\mathrm{t}), \mathrm{X}^{\mathrm{Q}}(\mathrm{t})$ in certain periods of $t_{1}, t_{2}, t_{3}$ and $t_{4}$.

As shown in the plot of Figure 3 for the supply cost model, some peaks of expenses or cost can be observed. The costs according to the Table 2, from time periods 1 to 4 through whole domain are disorderly decreased. As can be observed in the plot of Figure 3 for the supply cost model, some peaks of expenses or cost can be observed.

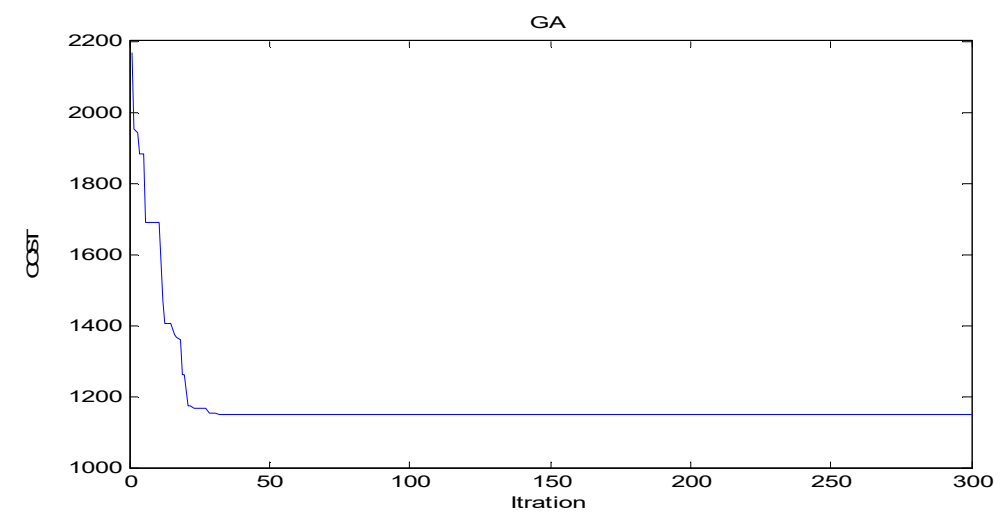

Figure 3. The plot for cost on supply manufacturing system in MATLAB.

In Figure 4 the plot shows the production cost model and more costly than supply operation system that obtained in MATLAB. 


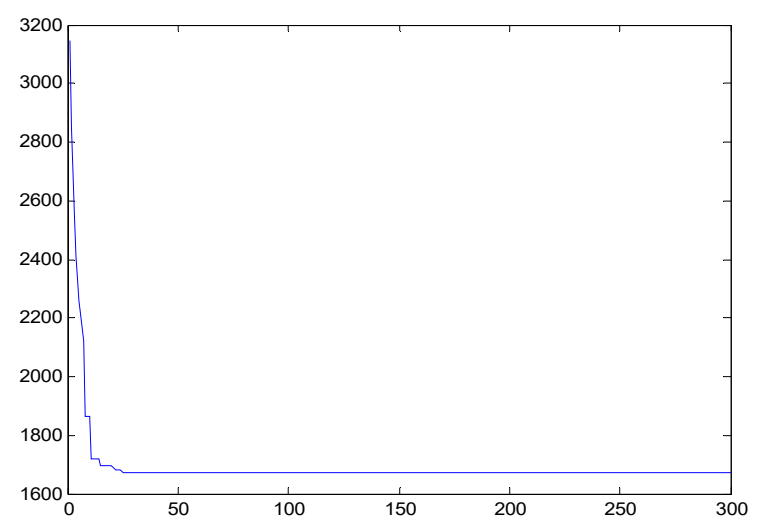

Figure 4. The plot for cost on production manufacturing system in MATLAB.

In Figure 5 the plot shows the production cost model with a noticeable change of cost with a peak as obtained in MATLAB.

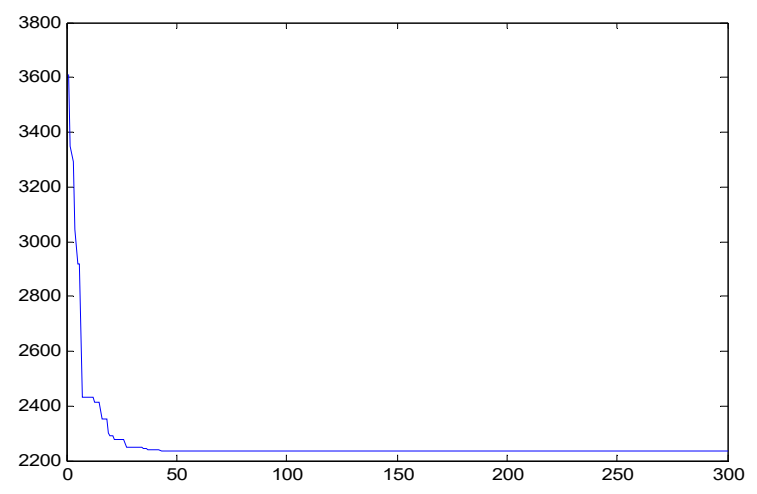

Figure 5. The plot for cost on distribution manufacturing system in MATLAB.

As can be seen, the obtained results through above models of supply, production, and distribution show that the costs are not desirable based on expert's ideas and decision makers. Therefore, the experts find better results as follows, and the costs and expenses are integrated into the model through the process.

In Figure 6 the plot shows the cost model for integrated supply chain system with a significant curve as far from the axis that obtained in MATLAB.

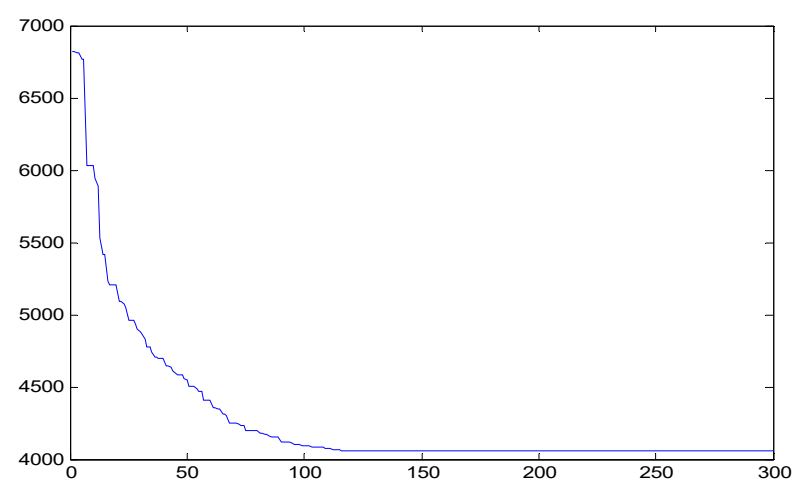

Figure 6. The plot for Total cost of integrated manufacturing function in MATLAB.

The last results confirms that the integrated costs model is the optimum solution in comparison with the total cost of three models supply, production and distribution through the certain time periods of $1,2,3$ and 4 . 


\section{Discussion}

In the current research paper, several different models and methods have been used to obtain the result by computations to evaluate and study the supply chain performances regarding the research problems. By integrating the whole reduction of the costs in supply chain segments that consists of the costs and expenses in supply, production, and distribution, we proposed to solve the research problems by reducing and minimizing the missing investing money. The more cost-oriented supply chain decision making is, the higher expected investment on integrated functions of supply, production and distribution will be. Meanwhile, the bottlenecks will be tackled and solved fundamentally from early steps in supply chain to make the products at end, with achieving the supply chain profitability and assets.

The computational and operational research plans are obtained through the method MATLAB. Therefore, all the missing investment money will be controlled and as far as it is possible minimizing them in an integrated illustrated model and structure which would be more applicable than minimizing the individual segment in supply chain management mechanism. The greatest costs are happened in the distribution section of supply chain system according to the total operational costs in supply, production, and distribution models are obtained as 1148, 1674, and 2234 respectively. The total optimization cost for all three segments is measured to be about 5056, however, regarding the costs in integrated model data mentioned from Table 5, which is 4058 obtained by MATLAB estimation (total cost reduced approximately 19.73\%). Due to the investigation on bottleneck in distribution, the distribution segment or warehouse should control the loading and unloading system properly and costly. Missing widgets or costs of warehouses in manufacturing system caused the supply chain system to come to a halt. The managers and decision makers have to prevent the risk of bottlenecks increasing by providing particular affairs. The computations of supply, production, and distribution models and mixed integrated model have been based on 'supply risk', 'production risk' and 'distribution risk' with regarding to profitability impacts to procure the supply chain system how it can maximize while minimize the risk. However, bottleneck sits on the climax of risks that lead to low profit. Here, unloading the products through causes in the warehouses and distribution segment created the important bottleneck. In this situation, the assisting of one lapse of concentration will help the supply chain system. If the system runs into this situation where the managers should stop production and they immediately engage all the relevant departments and affairs to fix it such as technical, production, customer service, logistics, and quantity or amount. Through getting the strategies and process, the supply chain manufacturing system has mitigated the risk and bottleneck on supply, production, and distribution processing systems through mixed integer nonlinear programing (MINLP) and using MATLAB. We now evaluate the throughput of supply chain operational system that is achieved by various supply chain models in situation. Integrating between operations can eliminate bottlenecks through optimizing the cost zone and services costs.

\section{Conclusions}

Three different multi-objective models were developed in this study to show different evaluation for calculating the total cost in segments of manufacturing and integrated model with regard to minimizing the cost in manufacturing supply chain system. As can be seen through the single models, the distribution cost is the highest in manufacturing process that must be controlled by the decision makers and authorities. The total integrated supply chain approach has superior results over decoupled integrated approach, obviously. We evaluate the manufacturing models functionality referring to the collecting data from a real case study. Finally, by applying software MATLAB, we solve the problem as mixed integer nonlinear programming with multi-objective models. All the results by software MATLAB support the validity of our models. In the results, a comparison between the integrated cost model of supply chain and the individual model of supply chain was executed to confirm the advantages of the integrated mathematical modelling and simulation. According to this solution and respecting the pre-requisites of implementations in integrated supply chain including the 
initial quality of raw material in physical and chemical testing for combination in formula, undefeated machinery and devices, skilled workers, on-time drivers for transportation system, etc., the investors are being suggested and recommended to apply the integration system thoroughly, as even partial integration and not full integration of supply, production, and distribution segments, can achieve profits. As the mathematical models in this study as MINLP models were developed through MATLAB while the optimum solution can be obtained by LINGO or other software. The lack of data throughout the manufacturing system caused unknowledgeable efficiencies on how much improve the facilities, labor and equipment for production and how much raises safety, accurate inventory, boost throughput and profits to prolong the life of supply chain processing and handling. Considering the models, it can be found that the distribution part in supply chain system is using the most costs of investment. Meanwhile, the warehouse has to be controlled and the process and the loading system properly and cost-effectively managed. Since the warehouse expenses are calculated by placing any new order and followed production flow to perform the essential steps in the process of distribution centers that needs efficient space and labors for sorting, packing, picking, loading, and storing in warehouses even some are done in parallel just to prevent and avoid lost orders by the other new customers and purchasers. The managers should decide to minimize these costs as much as they can. To avoid and eliminate this bottleneck and congestion, there is a need to minimize the costs by integrating the operations of supply, production, and distribution to be well-functioned and efficient for a new product and maximize the performance and throughputs to optimize the productivity and profitability. The integration of supply chain operations can mitigate the bottlenecks in costs through optimizing the cost zone and services costs. The bottleneck in the warehouse caused the fulfillment of product handling systems to be halted by frequent breakdown. This suffering of frequent breakdown malfunctions of warehouse operations leads to loss in productivity that has a direct effect on the profitability of construction manufacturing supply chain cost system. The supply chain manufacturing system will fail to continue manufacturing and production when the bottlenecks are not eliminated yet to do scheduling and preventing maintenance. Unloaded and undelivered products in warehouses not only occupied the warehouses space and place but also increase the maintenance service and holding costs in rising amount that will negatively effect on investment in plant for new product by new customer's order. Finally, the future product would develop as an uncertain pricing and customer's demand causing different unmentioned reasons such as procurement planning or higher purchasing cost, as well as holding cost of models of higher inventory. Accessing the right information in large amounts is required and valuable for supply chain manufacturing system to get logical results, makes decisions, and increase the speed of operating. Data collecting and analyzing in all sections, patterns, and processes are required such as number of handled orders, shipped materials and their costs to consider how well the output will be achieved. Big data can offer valuable insights into all kinds of patterns and processes. The lack of data throughout the manufacturing system causes unknowledgeable efficiencies to determine how much improves the facilities, labor and equipment for production and how much raises safety, accurate inventory, boost throughput, and profits to prolong the life of supply chain processing and handling.

In future research work of investigation on bottlenecks, it is suggested that the sharing system of budget can include bottlenecks in any process of marketing, outsourcing of some operations such as producing Aluminum mash, professional testing of raw materials in scientific laboratories, in large amounts of production that needs more attention by decision makers and investors to increase the number of distribution centers or other decisions in situation. By considering the usual limitations in budget and the well-done pricing procedure for product, an extension can be suggested to study the integration of sales with supply chain. In addition, there is a need to develop the evaluation methods and tools that will support researchers' work in different situations. Developing such a tool or method can also be suitable for the managers and investors to analyze qualified data properly for identifying the bottlenecks in functions and solving the particular problem by professional processing handling. 
Author Contributions: Conceptualization, M.H. and H.S.; Data curation, M.H.; Formal analysis, M.H. and H.S.; Funding acquisition, H.S.; Investigation, M.H.; Methodology, M.H. and H.S.; Project administration, H.S.; Resources, H.S.; Software, M.H. and H.S.; Supervision, H.S.; Validation, M.H. and H.S.; Visualization, M.H.; Writing—original draft, M.H.; Writing—review \& editing, M.H. and H.S.

Funding: This research was funded by Nanjing Province government (Award No. 14001473).

Conflicts of Interest: The authors have no conflict of interest.

\section{References}

1. Lummus, R.R.; Krumwiede, D.W.; Vokurke, R.J. The relationship of logistics to supply chain management: Developing a common industry definition. Ind. Manag. Data Syst. 2001, 101, 426-432. [CrossRef]

2. Lee, C.W.; Kwon, I.; Severance, D. Relationship between supply chain performance and degree of linkage among suppliers, internal integration, and customer. Supply Chain Manag. 2007, 12, 444-452. [CrossRef]

3. Vaart, T.; Donk, D.P. A critical review of survey-based research in supply chain integration. Int. J. Prod. Econ. 2008, 111, 42-55. [CrossRef]

4. Sawik, T. Integrated supply, production and distribution scheduling under disruption risks. Omega Int. J. Manag. Sci. 2015, 62, 131-144. [CrossRef]

5. Jabbarzadeh, A.; Fahimnia, B.; Sheu, J. An Enhanced Robustness approach for managing supply and demand uncertainties. Int. J. Prod. Econ. 2015, 183, 620-631. [CrossRef]

6. Nemati, Y.; Alavidoost, M.H. A Fuzzy bi-objective MILP approach to integrate sales, production, distribution and procurement planning in a FMCG supply chain. Soft. Comput. 2018, 1-20. [CrossRef]

7. Jolai, F.; Gharaei, A. A multi-agent approach to the integrated production scheduling and distribution problem in multi-factory supply. J. Appl. Soft Comput. 2018, 65, 577-589. [CrossRef]

8. $\quad$ Leung, J.Y.T.; Li, K.; Zhou, C.; Ma, Y. Integrated production and delivery with single machine and multiple vehicles. Expert Syst. Appl. 2016, 57, 12-20. [CrossRef]

9. Rohmer, S.; Billaut, J.C. Production and outbound distribution scheduling: A two-agent approach. In Proceedings of the International Conference on Industrial Engineering and Systems Management (IESM), Seville, Spain, 21-23 October 2015; pp. 135-144. [CrossRef]

10. Foerstl, K.; Schleper, M.C.; Henke, M. Purchasing and supply management: From efficiency to effectiveness in an integrated supply chain. J. Purch. Supply Manag. 2017, 23, 223-228. [CrossRef]

11. Khan, M.; Jaber, M.Y.; Ahmad, A. An integrated supply chain model with errors in quality inspection and learning in production. Int. J. Prod. Econ. 2014, 42, 16-24. [CrossRef]

12. Chung, S.H.; Kwon, C. Integrated supply chain management for perishable products: Dynamics and oligopolistic competition perspectives with application to pharmaceuticals. Int. J. Prod. Econ. 2016, 179, 117-129. [CrossRef]

13. Aqlan, F.; Lam, S.S. A fuzzy-based integrated framework for supply chain risk assessment. Int. J. Prod. Econ. 2015, 161, 54-63. [CrossRef]

14. Hu, G.; Zhang, Y.; Brown, R.C. Integrating supply chain design for commodity chemicals production via woody biomass fast pyrolysis and upgrading. J. Bioresour. Technol. 2014, 157, 28-36. [CrossRef]

15. Diabat, A.; Al-salem, M. An integrated supply chain problem with environmental considerations. Int. J. Prod. Econ. 2015, 164, 330-338. [CrossRef]

16. Diabat, A.; Deskoores, R. A hybrid genetic algorithm based heuristic for an integrated supply chain problem. J. Manuf. Syst. 2016, 38, 172-180. [CrossRef]

17. Gunasekaran, A.; Wang, G.; Ngai, E.W.T.; Papadopoulos, T. Big data analytics in logistics and supply chain management: Certain investigations for research and applications. Int. J. Prod. Econ. 2016, 176, 98-110. [CrossRef]

18. Shaye Sani, M.; Jalilian, I.; Sorbi, S.; Zorrieh, S. The role of management in the evolution of the Company's Supply Chain. Eur. J. Manag. Mark. Stud. 2017, 2, 176-187. [CrossRef]

19. Pishvaee, M.S.; Babazadeh, R.; Razmi, J.; Rabbani, M. An integrated data envelopment analysis-mathematical programming approach to strategic biodiesel supply chain network design problem. J. Clean. Prod. 2015, 147, 694-707. [CrossRef]

20. Ferrell, W.; Devapriya, P.; Geismar, N. Integrated production and distribution scheduling with a perishable product. Eur. J. Oper. Res. 2017, 259, 906-916. [CrossRef] 
21. Zegordi, S.H.; Marandi, F. Integrated production and distribution scheduling for perishable products. Sci. Iran. 2017, 24, 2015-2118. [CrossRef]

22. Moin, N.H.; Yuliana, T. Three-Phase Methodology Incorporating Scatter Search for Integrated Production, Inventory, and Distribution Routing Problem. Hindawi Math. Probl. Eng. 2015, 2015. [CrossRef]

23. Azadian, F.; Murat, A.; Chinnam, R.B. Integrated production and logistics planning: Contract manufacturing and choice of air/surface transportation. Eur. J. Oper. Res. 2015, 247, 113-123. [CrossRef]

24. Stadtler, H. Supply chain Management: An overview. In Supply Chain Management and Advanced Planning; Springer: Berlin, Germany, 2015; pp. 3-28.

25. Bektas, T.; Paksoy, T.; Ozceylan, E. Modeling and optimizing the integrated problem of closed-loop supply chain network design and disassembly line balancing. Transp. Res. Part E: Logist. Transp. Rev. 2013, 61, 142-164. [CrossRef]

26. Gale, G.; Polo, L.; Calvete, H.I. Integrated Supply Chain Planning: A Review. Model. Simul. Eng. Econ. Manag. 2016, 92-103. [CrossRef]

27. How, B.S.; Yeoh, T.T.; Tan, T.K.; Chong, K.H.; Ganga, D.; Lam, H.L. Debottlenecking of sustainability performance for integrated biomass supply chain: P-graph approach. J. Clean. Prod. 2018, 193, 720-733. [CrossRef]

28. Wendt, A.S.; Stephenson, R.; Young, M.F.; Verma, P.; Srikantiah, S.; Webb-Girard, A.; Hogue, C.J.; Ramakrishnan, U.; Martorell, R. Identifying bottlenecks in the iron and folic acid supply chain in Bihar, India: A mixed-methods study. BMC Health Serv. Res. 2018, 18, 281. [CrossRef]

29. Mathiyazhagan, K.; Datta, U.; Singla, A.; Krishnamoorthi, S. Identification and prioritization of motivational factors for the green supply chain management adoption: Case from Indian construction industries. Opsearch 2018, 55, 202-219. [CrossRef]

30. Soda, S.; Sachdeva, A.; Garg, R.K. Implementation of green supply chain management in India: Bottlenecks and remedies. Electr. J. 2016, 29, 43-50. [CrossRef]

31. How, B.S.; Lam, H.L. PCA Method for Debottlenecking of Sustainability Performance in Integrated Biomass Supply Chain. Process Integr. Optim. Sustain. 2018, 1-22. [CrossRef]

32. Oliveira, M.P.; Handfield, R. Analytical foundations for development of real-time supply chain capabilities. Int. J. Prod. Res. 2018, 1-9. [CrossRef]

33. Li, C.; Yun, J.; Ding, T.; Liu, F.; Ju, Y.; Yuan, S. Robust Co-Optimization to Energy and Reserve Joint Dispatch Considering Wind Power Generation and Zonal Reserve Constraints in Real-Time Electricity Markets. Appl. Sci. 2017, 7, 680. [CrossRef]

34. Feng, L.; Zhang, H.; Chen, Y.; Lou, L. Scalable Dynamic Multi-Agent Practical Byzantine Fault-Tolerant Consensus in Permissioned Blockchain. Appl. Sci. 2018, 8, 1919. [CrossRef]

35. Gurgen Erdogan, T.; Tarhan, A. A Goal-Driven Evaluation Method Based on Process Mining for Healthcare Processes. Appl. Sci. 2018, 8, 894. [CrossRef]

36. Beer, J.E. Analysis and Management of Bottlenecks in Supply Networks: Towards a Structured Approach to Stabilization of Inbound Material Flow. Ph.D. Thesis, University of Stavanger, Stavanger, Norway, 2015.

37. Mizgier, K.J.; Jüttner, M.P.; Wagner, S.M. Bottleneck identification in supply chain networks. Int. J. Prod. Res. 2013, 51, 1477-1490. [CrossRef]

38. Jain, S.; Gan, B.P.; Lim, C.C.; Low, Y.H. Bottleneck based modeling of semiconductor supply chain. In Proceedings of the International Conference on Modeling and Analysis of Semiconductor Manufacturing, Tempe, Arizona, 10-12 May 2000.

39. Min, H.; Eom, S. An Integrated Decision Support System for Global Logistics. Int. J. Phys. Distrib. Logist. Manag. 1994, 24, 29-39. [CrossRef]

40. Watson, R.; Pitt, L. Remarrying Marketing and Logistics with Information Systems Technology. Ind. Manag. Data Syst. 1989, 89, 4-12. [CrossRef]

(C) 2019 by the authors. Licensee MDPI, Basel, Switzerland. This article is an open access article distributed under the terms and conditions of the Creative Commons Attribution (CC BY) license (http://creativecommons.org/licenses/by/4.0/). 